\title{
Measurement of User Satisfaction Level in the Bina Darma Information Systems Study Program Portal Using End User Computing Satisfaction Method
}

\section{Pengukuran Tingkat Kepuasan Pengguna pada Portal Program Studi Sistem Informasi Bina Darma Menggunakan Metode End User Computing Satisfaction}

\author{
Nurul Adha Oktarini Saputri ${ }^{1}$, Alvin ${ }^{2}$ \\ ${ }^{1}$ Teknik Informatika, Universitas Bina Darma, Palembang, Indonesia \\ 2Sistem Informasi, Universitas Bina Darma, Palembang, Indonesia \\ Email: 1nuruladhaos@binadarma.ac.id, 2alvin151410106@gmail.com
}

\begin{abstract}
Information systems study program portal is a website developed by Bina Darma University that aims to be a media for promotion and academic information system study programs. User satisfaction is the most important thing to be a benchmark for developers of information systems study program portals to improve the quality of their websites so that users are more satisfied and do a lot of searching activities, especially academic activity searches. But so far the information systems study program portal developer does not yet know the shortcomings of the information system study program portal, so analysis is needed to measure the level of user satisfaction. In an effort to achieve User Satisfaction with the portal of the bina darma information system study program which has the si.binadarma.ac.id domain, researchers used the end user satisfaction method (EUCS). The EUCS instrument includes five components: content, accuracy, format, ease of use, and schedule. The data in this study were collected with a questionnaire instrument that was distributed to students from the information systems study program. Furthermore, the data obtained were processed using SPSS software version 24 . The sampling technique used in this study was simple random sampling. The results of this study are expected to be a reference to improve the quality of information systems study program portals.
\end{abstract}

Keywords: website, user satisfaction, EUCS

\section{PENDAHULUAN}

Perkembangan ilmu pengetahuan teknologi (IPTEK) saat ini semakin pesat semua ini tidak lepas dari pemikiran-pemikiran manusia yang semakin berkembang dan maju, hal ini dapat dilihat dari ilmu komputer yang berkembang 
semakin pesat. Penyebaran informasi tidak hanya bisa didapatkan melalui media cetak saja tetapi bisa didapatkan melalui media elektronik seperti internet.

Portal program studi sistem informasi merupakan website yang dikembangkan oleh universitas bina darma yang bertujuan untuk menjadi media promosi dan informasi akademik program studi sistem informasi. Namun dari data yang peneliti dapatkan, portal program studi sistem informasi masih memiliki kekurangan diantaranya informasi yang kurang update artinya informasi yang ditampilkan di website: si.binadarma.ac.id tidak terbaru contohnya pada menu pengumuman informasi yang ditampilkan belum diperbarui, sehingga diperlukan analisis untuk mengukur tingkat kepuasaan pengguna.

Dalam upaya mencapai kepuasan pengunaan terhadap portal program studi sistem informasi bina darma yang berdomain si.binadarma.ac.id peneliti menggunakan metode end user computing satisfaction (EUCS). Instrumen end user computing satisfaction (EUCS) mencakup lima komponen: isi (content), keakuratan (accuracy), bentuk (format), kemudahan penggunaan (ease of use) dan ketepatan waktu (timeliness). Selanjutnya data dalam penelitian ini di kumpulkan dengan instrumen kuesioner dan studi pustaka yang di sebarkan kepada mahasiswa program studi sistem informasi bina darma dan dosen sistem informasi. Selanjutnya data yang diperoleh diolah menggunakan software SPSS versi 24. pengambilan sample yang di gunakan dalam penelitian ini adalah simple random sampling. Hasil analisanya berupa pernyataan-pernyataan yang menilai kelemahan dan kekurangan atau baik dan buruknya portal program studi sistem informasi.

\section{METODE}

End User Computing Satisfaction (EUCS) “adalah metode untuk mengukur tingkat kepuasan dari pengguna suatu sistem aplikasi dengan membandingkan antara harapan dan kenyataan dari sebuah sistem informasi. Definisi End User Computing Satisfaction dari sebuah sistem informasi adalah evaluasi secara keseluruhan dari para pengguna sistem informasi yang berdasarkan pengalaman mereka dalam menggunakan sistem tersebut" [1]. EUCS "merupakan alat untuk mengukur tingkat kepuasan pengguna suatu sistem atau aplikasi dan hasilnya akan dianalisis menggunakan metode statistik. Variabel EUCS terdiridari lima variabel, yaitu: isi, keakuratan, bentuk, kemudahan dan ketepatan waktu" [2]. "Sebagai instrument dalam pengukuran kepuasan menggunakan end user computing satisfaction (EUCS) yang telah terbukti sebagai alat ukur yang sistematis dan akurat" [3].

\subsection{Metode Penelitian}

Metode penelitian yang digunakan dalam penelitian ini menggunakan metode kuantitatif. Metode ini sebagai metode ilmiah, obyektif, terukur, rasional, dan 
sistematis. Metode kuantitatif "adalah metode penelitian yang berlandaskan pada filsafat positivisme, digunakan untuk meneliti pada populasi atau sampel tertentu, pengumpulan data menggunakan instrument penelitian, analisis data bersifat kuantutatif atau statistik, dengan tujuan untuk menguji hipotesis yang telah ditetapkan" [4].

\subsection{Populasi dan Sampel}

Jenis pengambilan sampel dalam penelitian ini menggunakan Simple random sampling. Dikatakan simple (sederhana) "karena pengambilan anggota sampel yang memberikan peluang yang sama bagi setiap unsur (anggota) populasi untuk dipilih menjadi anggota sampel" [4].

Adapun sampel dalam penelitian ini ialah mahasiswa bina darma jurusan sistem informasi dan dosen sistem informasi bina darma. Agar dapat menentukan jumlah sampel dalam penelitian ini menggunakan rumus Slovin adalah sebagai berikut:

$$
n=\frac{N}{1+\left(N \cdot e^{2}\right)}
$$

$$
\begin{aligned}
\text { Keterangan : } & n=\text { Ukuran Sampel } \\
\mathrm{N} & =\text { Ukuran Populasi } \\
\mathrm{e}^{2} & =\text { Batas Toleransi Kesalahan }
\end{aligned}
$$

Kesalahan dalam pengambilan sample yang masih dapat di toleril 10\%. Populasi mahasiswa sistem informasi universitas bina darma sebesar 1930 mahasiwa aktif dan 40 dosen tetap (sumber: http:/ forlap.ristekdikti.go.id di akses pada 21 Januari 2019) dengan kerentanan kesalahan $10 \%$ maka;

$$
\begin{aligned}
n & =\frac{N}{1+\left(N \cdot e^{2}\right)} \\
\text { Sehingga } n= & \frac{1970}{1+1970.0,1^{2}} \\
n & =\frac{1970}{1+(1970.0,01)} \\
n & =\frac{1970}{1+19.7} \\
n & =\frac{1970}{20.7} \\
n & =95,169
\end{aligned}
$$

Maka dari jumlah populasi sebanyak 1970 dengan tingkat kesalahan sebesar 10\%, maka dengan menggunakan rumus slovin diperoleh sampel sebesar 95 sampel. 


\subsection{Skala Pengukuran}

Dalam penelitian ini skala likert digunakan sebagai pedoman penafsiran. Skala likert "digunakan untuk mengukur sikap atau pendapat seseorang atau sejumlah kelompok terhadap sebuah fenomena sosial yang dimana jawaban setiap item instrumen mempunyai gradasi dari sangat positif sampai sangat negatif. Dengan skala likert yang diukur dijabarkan menjadi indikator variabel" [5]. Skala memberikan penilaian dengan tingkatan angka yang sesuai dengan tingkat pengalaman dan penilaian menurut para responden.

Table 1. Skala likert[2]

\begin{tabular}{|c|c|c|c|c|c|}
\hline \multicolumn{6}{|c|}{ Keterangan skala tingkat kepuasan di dalam kuesioner } \\
\hline Angka & 1 & 2 & 3 & 4 & 5 \\
\hline Keterangan & $\begin{array}{c}\text { Sangat tidak } \\
\text { puas }\end{array}$ & $\begin{array}{c}\text { Tidak } \\
\text { puas }\end{array}$ & $\begin{array}{c}\text { Cukup } \\
\text { puas }\end{array}$ & Puas & $\begin{array}{c}\text { Sangat } \\
\text { puas }\end{array}$ \\
\hline
\end{tabular}

\section{HASIL DAN PEMBAHASAN}

Hasil yang akan didapat dalam penelitian ini adalah tingkat kepuasan pengguna pada portal studi sistem informasi bina darma. Metode yang digunakan dalam penelitian ini adalah metode end user computing satisfaction (EUCS). Penelitian ini akan membahas mengenai pengaruh dari ke lima variabel EUCS yaitu isi (content), akurasi (accuracy), bentuk (format), kemudahan penggunaan (easy of use), dan ketepatan waktu (timeliness) terhadap kepuasan pengguna (user satisfaction).

\subsection{Hasil Uji Validitas}

Uji validitas dilakukan menggunakan teknik korelasi Pearson Product Moment dengan mengkorelasikan masing-masing pertanyaan dengan jumlah skor/nilai masing-masing variabel. Angka korelasi yang diperoleh secara statistik harus dibandingkan dengan angka kritik tabel korelasi nilai $\mathrm{r}$ dengan taraf signifikan $5 \%$. Dalam penelitian ini didapatkan $r$-tabel sebesar 0,202. Bila $r$ hitung $>r$ tabel maka data tersebut dinyatakan valid dan bila $\mathrm{r}$ hitung $<$ dari $\mathrm{r}$ tabel maka data tersebut tidak valid.

Tabel 2. Hasil uji validitas

\begin{tabular}{|c|c|c|c|c|}
\hline Variabel & Pertanyaan & $\mathrm{r}$ hitug & $\mathrm{r}$ tabel & keterangan \\
\hline \multirow{3}{*}{ Content } & $\mathrm{C} 1$ & 0,690 & 0,202 & Valid \\
\cline { 2 - 5 } & $\mathrm{C} 2$ & 0,662 & 0,202 & Valid \\
\hline
\end{tabular}


Vol. 2, No. 1, March 2020

p-ISSN: 2656-5935 http://journal-isi.org/index.php/isi e-ISSN: 2656-4882

\begin{tabular}{|c|c|c|c|c|}
\hline \multirow{4}{*}{ accuracy } & C3 & 0,727 & 0,202 & Valid \\
\cline { 2 - 5 } & $\mathrm{C} 4$ & 0,599 & 0,202 & Valid \\
\hline & $\mathrm{A} 1$ & 0,625 & 0,202 & Valid \\
\cline { 2 - 5 } & $\mathrm{A} 2$ & 0,639 & 0,202 & Valid \\
\hline \multirow{4}{*}{ format } & $\mathrm{A} 3$ & 0,381 & 0,202 & Valid \\
\cline { 2 - 5 } & $\mathrm{F} 1$ & 0.841 & 0,202 & Valid \\
\cline { 2 - 5 } & $\mathrm{F} 2$ & 0,794 & 0,202 & Valid \\
\cline { 2 - 5 } Easy of use & $\mathrm{F} 3$ & 0,784 & 0,202 & Valid \\
\cline { 2 - 5 } & $\mathrm{E} 1$ & 0,767 & 0,202 & Valid \\
\cline { 2 - 5 } Timeliness & $\mathrm{E} 2$ & 0,789 & 0,202 & Valid \\
\cline { 2 - 5 } & $\mathrm{E} 3$ & 0,709 & 0,202 & Valid \\
\cline { 2 - 5 } & $\mathrm{T} 1$ & 0.774 & 0,202 & Valid \\
\hline & $\mathrm{T} 2$ & 0,785 & 0,202 & Valid \\
\hline
\end{tabular}

Sumber: Diolah dari data primer meggunkan SPSS versi 24

\subsection{Hasil Uji Reliabilitas}

Uji reliabilitas untuk mengukur konsistennya jawaban responden terhadap item-item pertanyaan yang terdapat di kuesioner. Pengujian ini hanya akan dilakukan untuk butir-butir pertanyaan yang valid, dimana pertanyaan yang valid diperoleh melalui pengujian validitas. Untuk menguji reliabilitas menggunakan uji statistik Alpha Cronbach, variabel dapat dikatakan reliabel jika memberikan nilai a $>0,60$.

Tabe1 3. Hasil uji reliabilitas

\begin{tabular}{|l|l|l|l|}
\hline Variabel & $\mathrm{r}$ hitung & $\mathrm{r}$ tabel & Keterangan \\
\hline Content & 0,763 & 0,60 & Reliabel \\
\hline Accuracy & 0,675 & 0,60 & Reliabel \\
\hline Format & 0,727 & 0,60 & Reliabel \\
\hline Easy of use & 0,621 & 0,60 & Reliabel \\
\hline Timeliness & 0,669 & 0,60 & Reliabel \\
\hline
\end{tabular}

Sumber: Diolah dari data primer meggunkan SPSS versi 24

\subsection{Hasil Uji $\mathbf{R}^{2}$}

Uji $\mathrm{R}^{2}$ digunakan untuk melihat seberapa besar pengaruh variabel $\mathrm{X}$ terhadap variabel Y. Berikut adalah hasil dari $\mathrm{Uji}^{2}$ : 
Vol. 2, No. 1, March 2020

p-ISSN: 2656-5935 http://journal-isi.org/index.php/isi e-ISSN: 2656-4882

Tabel 4. Uji R ${ }^{2}$

\begin{tabular}{|c|c|c|c|c|}
\hline \multicolumn{5}{|c|}{ Model Summary } \\
\hline Model & $\mathrm{R}$ & $\mathrm{R}$ Square & $\begin{array}{c}\text { Adjusted R } \\
\text { Square }\end{array}$ & $\begin{array}{c}\text { Std. Error of the } \\
\text { Estimate }\end{array}$ \\
\hline 1 &, $772^{\mathrm{a}}$ &, 596 &, 573 & 1,90543 \\
\hline
\end{tabular}

a. Predictors: (Constant), Timeliness, Easy of Use, Format, Accuracy,

\section{Content}

Sumber: Diolah dari data primer meggunkan SPSS versi 24

Dari tabel 4 diketahui nilai koefisiensi determinasi $\left(\mathrm{R}^{2}\right)$ sebesar 0,772 artinya variabel X secara simultan memberikan pengaruh terhadap variabel $\mathrm{Y}$ sebesar 0,573 atau $57,3 \%$.

\subsection{Hasil Uji T}

Pada dasarnya uji $\mathrm{T}$ menunjukkan seberapa besar jauh pengaruh satu variabel independent secara parsial dalam menerangkan variasi variabel dependent. Ho: bi $=0$, artinya "suatu variabel independent tidak berpengaruh terhadap variabel dependent. $\mathrm{H} 1: \mathrm{bi}=0$, artinya variabel independent berpengaruh terhadap variabel dependent. $\mathrm{H}: \mathrm{b}=0 ; \mathrm{t}-$ hitung $<\mathrm{t}-$ tabel atau $(\mathrm{p}>0,05)$, maka $\mathrm{H}$ diterima dan $\mathrm{H}$ ditolak. Hal ini berarti bahwa tidak ada pengaruh yang signifikan dari variabel Content secara parsial terhadap variabel kepuasan pemakai’'[6].

Tabel 5 Hasil uji $\mathrm{T}$

\begin{tabular}{|c|c|c|c|c|c|c|}
\hline & \multirow[b]{2}{*}{ Model } & \multicolumn{2}{|c|}{ Unstandardized Coefficients } & \multirow{2}{*}{$\frac{\text { Standardized Coefficients }}{\text { Beta }}$} & \multirow[b]{2}{*}{$\mathrm{t}$} & \multirow[b]{2}{*}{ Sig. } \\
\hline & & B & Std. Error & & & \\
\hline \multirow[t]{6}{*}{1} & (Constant) & 1,277 & 2,142 & & ,596 & ,553 \\
\hline & Content & ,061 & ,146 & ,099 & 1,097 & ,276 \\
\hline & Accuracy & 167 & ,187 & ,080 & 0,893 & ,374 \\
\hline & Format & ,405 & ,137 & 239 & 2,966 & ,004 \\
\hline & Easy of Use & ,726 & ,147 & ,400 & 4,949 &, 000 \\
\hline & Timeliness & 355 & , 166 & 200 & 2,141 & 035 \\
\hline
\end{tabular}

a. Dependent Variable: User Satisfaction $(\mathrm{Y})$

Sumber: Diolah dari data primer meggunkan SPSS versi 24

Dari tabel 5 diketahui terdapat 2 variabel $\mathrm{X}$ yang dinyatakan tidak berpengaruh terhadap variabel $\mathrm{Y}$, dan terdapat 3 variabel $\mathrm{X}$ yang dinyatakan berpengaruh terhadap variabel $\mathrm{Y}$, berikut penjelasan dari tiap variabel:

a. Hasil Uji t Variabel Content 
Dari tabel 5 diketahui nilai signifikansi dari variabel content sebesar 0,276 lebih besar dari nilai alpha 0,05 dan nilai $\mathrm{t}$ hitung sebesar 1,097 lebih kecil dari $\mathrm{t}$ tabel 1,665, artinya dapat disimpulkan bahwa variabel content tidak berpengaruh terhadap variabel $\mathrm{Y}$.

b. Hasil Uji t variabel Accuracy

Dari tabel 5 diketahui nilai signifikansi dari variabel accuracy sebesar 0,374 lebih besar dari nilai alpha 0,05 dan nilai thitung sebesar 0,893 lebih kecil dari t tabel 1,665, artinya dapat disimpulkan bahwa variabel accuracy tidak berpengaruh terhadap variabel $\mathrm{Y}$.

c. Hasil Uji t variabel Format

Dari tabel 5 diketahui nilai signifikansi dari variabel format sebesar 0,04 lebih kecil dari nilai alpha 0,05 dan nilai t hitung sebesar 2,966 lebih besar dari $\mathrm{t}$ tabel 1,665 , artinya dapat disimpulkan bahwa variabel format berpengaruh terhadap variabel $Y$.

d. Hasil Uji t variabel Ease of Use

Dari tabel 5 diketahui nilai signifikansi dari variabel ease of use sebesar 0,00 lebih kecil dari nilai alpha 0,05 dan nilai t hitung sebesar 4,949 lebih besar dari $\mathrm{t}$ tabel 1,665, artinya dapat disimpulkan bahwa variabel ease of use berpengaruh terhadap variabel $Y$.

e. Hasil Uji t variabel Timeliness

Dari tabel 5 diketahui nilai signifikansi dari variabel timelinness sebesar 0,35 lebih kecil dari nilai alpha 0,05 dan nilai t hitung sebesar 2,141 lebih besar dari t tabel 1,665, artinya dapat disimpulkan bahwa variabel timeliness berpengaruh terhadap variabel Y.

\subsection{Hasil Uji F}

Uji F digunakan untuk mengetahui pengaruh secara keseluruhan antara variabel independen yaitu content (X1), accuracy (X2), format (X3), ease of use (X4), dan timeliness (X5) terhadap variabel dependen yaitu user satisfaction $(\mathrm{Y})$. Jika nilai sig $<$ 0,05 , atau $\mathrm{F}$ hitung lebih besar dari $\mathrm{F}$ tabel maka terdapat pengaruh secara simultan terhadap variabel $\mathrm{Y}$, dan jika nilai sig $>0,05$, atau $\mathrm{F}$ hitug lebih kecil dari F tabel maka tidak terdapat pengaruh secara simultan terhadap Y.

Tabel 6. Hasil uji F

\begin{tabular}{|l|l|r|r|r|r|r|}
\hline \multicolumn{2}{|c|}{ Model } & $\begin{array}{c}\text { Sum of } \\
\text { Squares }\end{array}$ & df & Mean Square & F & Sig. \\
\hline \multirow{4}{*}{1} & Regression & 476,175 & 5 & 95,235 & 26,231 &, $000^{\mathrm{b}}$ \\
\cline { 2 - 7 } & Residual & 323,130 & 89 & 3,631 & & \\
\cline { 2 - 7 } & Total & 799,305 & 94 & & & \\
\hline
\end{tabular}

a. Dependent Variable: User Satisfaction $(\mathrm{Y})$ 
b. Predictors: (Constant), Timeliness (X5), Content (X1), Format (X3), Ease of Use (X4), Accuracy (X2)

Sumber: Diolah dari data primer meggunkan SPSS versi 24

Bedasarkan tabel 6 diketahui nilai signifikasi dari pengaruh variabel X secara simultan terhadap Y adalah sebesar 0,000 lebih kecil dari nilai alpha 0,05 dan $\mathrm{F}$ hitung sebesar 26,231 lebih besar dari $\mathrm{F}$ tabel 2,31 artinya dapat disimpulkan terdapat pengaruh variabel $\mathrm{X}$ secara simultan terhadap variabel $\mathrm{Y}$.

\section{KESIMPULAN}

Bedasarkan hasil pembahasan dan analisa yang telah dilakukan pada bab sebelumnya, maka dapat dibuat kesimpulan sebagai berikut:

1. Bedasarkan dari hasil $\mathrm{Uji} \mathrm{R}^{2}$ pada tabel 4 diketahui nilai kopesiensi determinasi (R2) sebesar 0,772 artinya variabel X yang terdiri dari content, accuracy, format, ease of use, dan timeliness secara simultan memberikan pengaruh terhadap variabel $Y$ yaitu user satisfaction sebesar 0,573 atau $57,3 \%$.

2. Bedasarkan dari hasil uji $\mathrm{T}$ terdapat 2 variabel yang tidak berpengaruh yaitu pada variabel content dan accuracy, dan terdapat 3 variabel yang berpengaruh yaitu format, easy of use dan timeliness.

3. Bedasarkan dari hasil Uji F

Diketahui nilai signifikasi dari pengaruh variabel $\mathrm{X}$ secara simultan terhadap $\mathrm{Y}$ adalah sebesar 0,000 < alpha 0,05 dan F hitung sebesar 26,231 > F tabel 2,31 artinya dapat disimpulkan terdapat pengaruh variabel $\mathrm{X}$ secara simultan terhadap variabel $\mathrm{Y}$.

\section{DAFTAR PUSTAKA}

[1] N. Dalimunthe and C. Ismiati, "Analisis Tingkat Kepuasan Pengguna Online Public Access Catalog (OPAC) Dengan Metode EUCS (Studi Kasus: Perpustakaan UIN SUSKA Riau)," J. Ilm. Rekayasa dan Manaj. Sist. Inf., vol. 2, no. 1, pp. 71-75, 2016.

[2] N. Halim, "Analisis End-User Computing Satisfaction (EUCS) Pada Aplikasi Mobile Universitas Bina Darma," Sist. J. Sist. Inf., vol. 9, no. 1, pp. 143-154, 2020.

[3] U. Ependi, R. Syafari, and P. Maharani, "End User Computing Satisfaction On Website Perpustakaan Daerah Sumatera Selatan," J. Teknol. Inf. Univ. Lambung Mangkurat, vol. 3, no. 1, pp. 35-46, 2018.

[4] Sugiyono, Metode Penelitian Kuantitatif, Kualitatif, dan RéD. Bandung: Alfabeta, 2017.

[5] D. Lusianti, "Pengukuran Kepuasan Peserta JKN Melalui Pendekatan Importance-Performance Analysis," J. Sains Pemasar. Indones. (Indonesian J. Mark. Sci., vol. 16, no. 1, pp. 17-25, 2017. 
Journal of Information Systems and Informatics

Vol. 2, No. 1, March 2020

p-ISSN: 2656-5935 http://journal-isi.org/index.php/isi e-ISSN: 2656-4882

[6] R. Dewa, Z. Mazalisa, and A. Putra, "Analisis Kepuasan Pengunaan Terhadap Portal Program Studi Informatika Menggunakan EUCS (End User Computing Satisfaction).” Skripsi. Universitas Binadarma. Palembang, 2016. 